DOI: 10.20472/IAC.2018.935.030

OSMAN METIN

Afyon Kocatepe University, Turkey

\title{
AN UNDERSTANDING OF SOCIAL MEDIA ADDICTION THROUGH A SOCIOLOGICAL APPROACH
}

\begin{abstract}
:
It is much better to investigate and understand the current/hot topics of society especially for social media. In this regard, social media addiction is one of the common issue that is assessed by many parties from the sociological perspective. Hereof, it is important to assess social media addiction as a type of addiction from a sociological perspective. Throughout this research, the sociological background of social media addiction will be tried to be establish by theoretically. To this end, relevant links of the features of modern and postmodern societies will be established and they will be associated with individualization. Subsequently, an answer will be sought to determine if a sociological solution to social media addiction can be developed or not.
\end{abstract}

\section{Keywords:}

social media, addiction, social media addiction 